\title{
Challenges and Prospects of Balanced Scorecard Implementation (Evidence from Bench-Maji Zone; South-West Ethiopia)
}

\author{
Alebel Woretaw Andualem Ayalew \\ Lecturer,College of business \& Economics,Mizan-Tepi University
}

\begin{abstract}
This study is concerned with the challenges and prospects in Bench-Maji Zone public sectors. To this end, the study has made an effort to thoroughly look into challenges and prospects that have taken surface in the whole performance management process and system. It has made an effort to identify and investigate challenges and prospects associated to the implementation of the Balanced Scorecard (BSC) which is being used by Bench-Maji Zone public sectors.85 employees and heads in the Zone have been taken as study participant and data have been collected using structured self administered questionnaire. 15 (heads of the sector) persons have also been contacted for in-depth interview from different sectors for triangulation purpose. The finding shows that the major challenges that the Zone faces is emanated from lack of commitment of top management officials, lack of understanding of the tool, early cascading and considering the tool more as a tool of measurement rather than a tool for strategic management. However; the tool is also helps the organization by increasing the organization performance, by communicating the organization mission, vision and strategic objective to employees, by creating team spirit and others. So to avoid the challenges it is recommended that the Zone should give training about the tool, the Zone should define the measurements, and after being sure that the metrics measure the activities of the business units and the selected measure is easily quantifiable.
\end{abstract}

Keywords: Balanced scorecard, challenges, prospects \& implementation

DOI: $10.7176 / \mathrm{JESD} / 12-13-01$

Publication date:July $31^{\text {st }} 2021$

\section{Introduction}

The Balanced Scorecard, developed by Kaplan and Norton (2010), enables management to translate the mission, the goals and the strategies of the company, its different business units and management functions into a coherent set of performance measures. This set of performance measures is divided into four perspectives: the shareholders' or financial perspective, which groups the measures assessing the extent to which the company realizes the shareholders' expectations; the customers' perspective which measures the perception of the company by its clients; the internal processes' perspective which determines the performance of critical internal processes; and the innovation and learning perspective which measures the learning ability, the growth potential and the improvement and change capacity.

With growing interest in improving performance management in organizations, the balanced score card can be a valuable tool that meets the need for improvement and change especially for companies venturing into very competitive or monopolistic market. It is a customer based plannisng and process improvement system with its primary focus on driving an organization's change process by identifying and evaluating pertinent performance measures. It is an integral part of the mission identification, strategy formulation and process execution, with an emphasis on translating strategy into a linked set of financial and non financial measures (Nzuve \& Nyaega,2008)

Nowadays, the private and public sector organizations throughout the world exercise balanced scorecard as change and strategic management system. In Ethiopia lots of public sector organizations have implemented balanced scorecard. However; the public organizations that employ balanced scorecard as change and strategic management system encountered difficulty with its design cascading and its implementation. Thus the researcher is motivated to undertake research on the challenges and prospects of balanced scorecard design and implementation; in the case of Bench-Maji Zone, South west Ethiopia, public sectors.

\section{Research Methodology}

In order to answer the research questions and the problems, the researcher used descriptive research method. Because this type of research describes what exists and may help to uncover new facts and meanings. This involves the collection of data that will provide an account or description of individuals, groups or situations. Instruments the researcher used to obtain data in descriptive studies include questionnaires (closed \& open ended questions), and interviews.

\section{Data source and data collection techniques}

In order to answer the research questions, several data collection methods are used to gather primary and secondary data. The primary data were collected through questionnaires, interview with sector's heads $\&$ employees. The secondary data were gathered from relevant documents. 


\section{Sampling design}

In order to obtain data about challenges and prospects of balanced scorecard in Bench-Maji Zone 20 public sectors were selected using purposive sampling technique. The companies were selected based on the experience and availability of an organized data for the study. On the other hand, employees were selected randomly, after proportional sample from each sector, based on their list, taken from human resource department. Accordingly, 85 employees from 20 public sectors were selected as a sample by using Yamane's (1967).

\section{Methods of data analysis}

In this study to analyze the collected data descriptive data analysis method were employed. Data collected through interviews was analyzed by using description of facts. Those data collected through questionnaires were analyzed using SPSS. Finally, researcher was validated the result by triangulating different data sources of information and examining evidence from the source to determine the accuracy of the findings. Adequate steps were taken to ensure the validity of the questionnaire. For its validity, content validity was determined. The results were presented through tables and charts.

\section{Results and Discussions}

\section{General information about respondents}

From the total respondents, $25 \%$ of the total respondents were females working in the Zone administration level public sectors. The percentage of male respondents constitutes the largest part $(75 \%)$. Indeed, the numbers of female respondents were not proportional, given the total number of female employees in the Zone.

The respondents were serving in 20 sector offices/units in the Zone administration. Thus, data have been gathered from 20 offices. We need to note that proportionality was maintained from each sectors from the total population and the target respondents was taken from the list of the total workforce which was listed based on their sector offices.

From the total respondents included in the study, 37\% and 33\% have served from 6 months to 1 year and 1 to 2 years respectively at the respective sectors. The collected data shows that, the number of respondents' decreases as the year of service increases. This is due to high turnover of staff in the study Zone,Bench-Maji.

\section{Performance Planning Using Balanced Scorecard (BSC)}

- Training on balanced scorecard: The findings indicated that $88.5 \%$ of the respondents had taken training on the performance management tool, balanced scorecard (BSC). The remaining $11.5 \%$ have never taken training on the performance management tool. We need to bear in mind that all the respondents have served in the Zone administration at least for 6 months as employees below six months service were excluded during the study population determination phase for the purpose of quality of the study.

- Frequency of training: According to the survey finding, 33\% and 17\% of the respondents have taken 1 and 2 times respectively. All the respondents who have never taken training and those who have taken the training 1 and 2 times were lower level and Officers/heads employees respectively. This reality shows that training opportunities were not accessible to employees working at the lower level of the government structure.

- Level of understanding: A significant number $(60.5 \%)$ of the respondents replied that all the workforce in the Zone do not have similar understanding about the performance management tool/BSC.

- Level of participation in organizational plan: More than $1 / 3$ of the respondents $(28.2 \%)$ have not taken part in the planning process. From those participated in the performance planning process $84.9 \%$ replied that the level of participation was from maximum $(30.2 \%)$ to medium $(54.7 \%)$. The remaining $15.1 \%$ responded the participation was low.

\section{Coaching and technical support}

All the respondents agreed that their offices were receiving coaching, technical support and guidance in issues pertinent to performance management. They receive these supports from two sources: the Capacity Building Office in the Zone administration which is mandated to coordinate, supervise and support sector offices in areas related to public sector reforms and performance management (planning, coaching and guidance, capacity building, evaluation and recognition).

- Level of satisfaction on coaching \& technical support: Though all the respondents agreed that their offices have been receiving coaching and technical support from the Zone Capacity Building Office and their subcity level line offices, only $53.5 \%$ are satisfied with the service they are receiving. The remaining $46.5 \%$ of the staff are either unsatisfied or highly unsatisfied with the service.

- Regularity of coaching \& technical support: More than half of the respondents (53.6\%) said that the coaching, technical support and guidance rendered to their offices were not well-planned and regularly done. In performance management, it is a general principle that coaching and technical support must be tailored to individual needs of the offices or individuals and should be offered on timely basis. 
- Capability of Individuals who are providing coaching, technical support: In responding to experience and expertise of the individuals assigned to provide coaching \& technical support, only $57.7 \%$ replied strongly agree or agree. The rest of the respondents $(42.3 \%)$ have disagreed or strongly disagreed that individuals who are providing coaching and technical support are competent enough to properly undertake their assignments.

\section{Balanced Scorecard (BSC) and performance improvement}

A significant percentage $(81.7 \%)$ of the individuals involved in the survey responded that the introduction of the performance management tool, balanced score card, has positively contributed to the performance improvement of their offices. According to the respondents, performance improvement have been seen in the areas of customer satisfaction, grievance and complaint management, and quality of services provided to the public, creation of strategy focused organizations, and speed of service delivery. However, $18.3 \%$ of the individuals involved in the study responded the introduction of BSC as performance management tool did not contribute to the performance improvement of offices.

\section{Organizational Performance measurement and evaluation}

In this study performance measurement and evaluation have been treated at two levels: organizational/sector office and individual employee. This section is concerned with presentation of findings in connection to organizational performance measurement and evaluation.

- Sectors Performance measurement \& evaluation system: Almost all (97.2\%) of the respondents who completed the questionnaire agreed that their offices have performance review and evaluation system. Only $2.8 \%$ of the individuals took part in the survey replied that their offices did not have performance review and evaluation system and procedure. The researcher has also observed that all the Zone public sector offices have systems and procedures to review and evaluate organizational performances.

- Regularity of sectors performance measurement $\&$ evaluation: The majority of the respondents (83.1\%) agreed that the performance review and measurements were being conducted regularly and based on predefined performance review system and procedure. However, the remaining $16.9 \%$ of the individuals completed the self-administered questionnaire responded that the review and measurement process was not based on performance review system and procedure.

- Sectors performance measurement \& evaluation in line with balanced scorecard: The main problem raised by the respondents $(53.5 \%)$ was that though performance review and measurement are regularly being conducted every quarter, the measurement was not based on organizational/office level scorecard and cascaded plan. The rest of the respondents $(46.5 \%)$ have strongly agreed or agreed that organizational performance review and measurements were based on the sectors/offices scorecard and the share that was cascaded to units and sub-units. From the document review in the Zone, the researcher has come to learn that performance measurements were not based on the scorecard.

\section{Individual employee performance appraisal and evaluation}

The preceding section has dealt with performance measurement and evaluation at the organizational/office level. This section focuses on findings of the survey in connection to performance appraisal and evaluation at individual employee level.

- Individual employee performance evaluation based on balanced score card: $65 \%$ of respondents disagree or strongly disagree that individual performance assessments were being done in line with the performance targets cascaded to them. This is associated to the fact that organizational/office level plans were not properly cascaded to individual employees.

\section{Conclusion}

Based on the finding of the study majority $(92 \%)$ of respondents replied that there is performance planning using balanced scorecard at the office/sector level. while there is a problem in the areas of even no first time and frequent training, difference in the level of understanding and participation on balanced score card.

A significant percentage $(81.7 \%)$ of the individuals involved in the survey responded that the introduction of the performance management tool, balanced score card, has positively contributed to the performance improvement of their offices. It is also cascaded in line with the sectors level but $65 \%$ of respondents disagree or strongly disagree that individual performance assessments were being done in line with the performance targets cascaded to them.

All the respondents agreed that their offices were receiving coaching, technical support and guidance in issues pertinent to performance management. They receive these supports from two sources: the Capacity Building Office in the Zone administration which is mandated to coordinate, supervise and support sector offices in areas related to public sector reforms and performance management (planning, coaching and guidance, capacity building, evaluation and recognition). But there is a problem of regular/frequent supervising, supporting, training \& updating 
the performance measurement tool, Balanced Scorecard.

\section{References}

Esu, B.B. \& Inyang, B.J. (2009) "A Case for Performance Management in the Public Sector in Harvard Business School. Harvard University.

Kairu, E. W. et al. (2013) "Effects of Balanced Scorecard on Performance of Firms in the Service Sector". European Journal of Business and Management, Vol.5, No.9, 2013.

Kaplan, R. \& Norton, D. (1996) The Balanced Scorecard: Translating Strategy into Action.Boston, MA: Harvard Business School Press.

Kaplan, R. S. and D.P. Norton (2001) The Strategy-Focused Organization: How Balanced

Kaplan, R.S. (2010) Conceptual Foundations of the Balanced Scorecard. Working Paper 10-074.

Nigeria". International Journal of Business and Management, Vol. 4, No. 4, 2009, pp.98-105.

Northcott, D. \& Taulapapa, T.M. (2012) "Using the Balanced Scorecard to Manage Performance in Public Sector Organizations: Issues and Challenges". International Journal of Public Sector Management, Vol. 25 Iss: 3 pp. 166 - 191. Retrieved from www.stellarleadership.com.Scorecard Companies Thrive in the New Competitive Environment. Boston: HBS Press.

Stellar Leadership Ltd. (2013) Introduction to the Balanced Scorecard for the Public Sector.

Stephen N.M Nzuve and Gabriel Nyaega School of Business, University of Nairobi.

Yamane, T., (1967): Statistics: An Introductory Analysis; Harber and Row, New York. 